\title{
O pensamento linguístico de Oswald Ducrot
}

\author{
Ânderson Rodrigues Marins ${ }^{\mathrm{i}}$
}

\section{RESUMO}

O presente estudo analisa o pensamento linguístico de Ducrot sobre os conectores de tipo lógico e os encadeadores de tipo discursivo, recapitulando noções de escala argumentativa e de classe argumentativa formuladas pelo linguista francês. Nota-se que as gramáticas da tradição têm dado maior ênfase ao estudo dos morfemas lexicais e dos morfemas gramaticais flexionais e derivacionais, relegando a um plano secundário o estudo dos operadores argumentativos, de tal forma que passam praticamente despercebidos ao estudante, que se limita a decorá-los. Recuperar tais elementos neste estudo encontra razão porque são justamente eles que determinam o valor argumentativo dos enunciados.

Palavras-chave: Oswald Ducrot; Conjunções; Linguística textual; Semântica argumentativa.

\begin{abstract}
The present study analyzes Ducrot linguistic thinking about logical type connectors and discursive type chaining, recapitulating argumentative scale and argumentative class notions formulated by the french linguist. It's noticed that the traditional grammars have given greater emphasis to the study of lexical morphemes and flexional and derivational grammatical morphemes, relegating to a secondary plan the study of argumentative operators, in such a way that they practically go unnoticed by the students, who are limited to decorate them. Recovering those elements in this study is justified because they determine the argumentative value of statements.
\end{abstract}

Keywords: Oswald Ducrot; Conjunctions; Textual linguistics; Argumentative semantics.

\footnotetext{
${ }^{\text {i }}$ Doutorando em Língua Portuguesa pela Universidade do Estado do Rio de Janeiro, Doutorando em Estudos de Linguagem pela Universidade Federal Fluminense, com Mestrado em Estudos de Linguagem e Graduação em Letras pela mesma instituição. É autor de livros, capítulos de livros e diversos artigos e desenvolve pesquisas sobre descrição do português, historiografia dos estudos linguísticos brasileiros, Linguística textual e Semântica argumentativa. ORCID: https://orcid.org/0000-0003-3152-0562 | andersonmarins @id.uff.br
} 


\section{INTRODUÇÃO}

Ducrot (1977), em sua Semântica Argumentativa, procura mostrar que, dentro do que a Gramática Tradicional considera como coordenação e subordinação, podemos identificar relações diferentes quanto à natureza e à organização dos enunciados. Assim, é possível distinguir dois tipos básicos de elementos de conexão interfrástica: os conectores de tipo lógico e os encadeadores de tipo discursivo.

A função dos conectores lógicos é apontar o tipo de relação lógica que o locutor estabelece entre o conteúdo de duas proposições. Nesse caso, trata-se de um único enunciado, resultante de um ato de fala único, já que nenhuma das proposições constitui objeto de um ato de enunciação compreensível independentemente da outra, ou seja, as duas orações estão ligadas num único ato de enunciação, correspondente a uma única intenção. Trata-se do que Ducrot considera como frases ligadas (cf. MARINS, 2017; 2021).

Para melhor explicar a noção de frases ligadas $^{1}$, Ducrot (1977, p. 129) introduz o conceito de predicado complexo ${ }^{2}$, constituído por um predicado elementar, sobre o qual agiram diferentes operadores, ou pela fusão de predicados elementares entre si. Esse predicado caracteriza as frases ligadas, que se poderiam considerar como verdadeiras subordinadas do ponto de vista semântico (ao contrário daquelas em que ocorre a coordenação semântica, na acepção de Bally). Os conectores que correspondem à estrutura da subordinação semântica e das frases ligadas constituem, assim, um conteúdo complexo a partir dos conteúdos simples expressos nas proposições $p$ e $q$. Forma-se, então, um predicado único e complexo do ponto de vista semântico; a segunda proposição se integra, de certa forma, num predicado único. As relações do tipo lógico, como as de condicionalidade, causalidade, mediação, temporalidade, complementação etc. correspondem a frases ligadas, dotadas de predicados complexos. Dessa forma, os operadores lógicos implicam subordinação semântica e um só universo de crenças.

\section{Os conectores de tipo lógico e os encadeadores de tipo discursivo}

As relações lógicas são as seguintes: 
a) Relação de condicionalidade: expressa pela conexão de duas orações, uma introduzida pelo conector se e outra por então (que pode estar implícito).

Exemplo:

1. Se chover muito (então) a rua ficará alagada.

b) Relação de causalidade: expressa pela combinação de duas orações, uma das quais encerra a causa que acarreta a consequência da outra.

Exemplo:

2. Passou mal porque bebeu demais.

Nas gramáticas tradicionais e nos livros didáticos, as orações que estabelecem essa relação de causalidade são chamadas de "causais" e "consecutivas".

c) Relação de mediação: expressa por duas orações numa das quais estão explicitados os meios para atingir a finalidade expressa na outra.

Exemplo:

3. Ele estudou muito para passar de ano.

Nas gramáticas tradicionais e nos livros didáticos, as orações que estabelecem essa relação de causalidade são chamadas de "finais".

d) Relação de conformidade: expressa por meio de duas orações em que se mostra a conformidade do conteúdo de uma em relação a outra.

Exemplo:

4. O menino agiu conforme o pai havia aconselhado.

Os encadeadores discursivos ${ }^{3}$, por outro lado, caracterizam o que Ducrot chama de coordenação semântica. São responsáveis pela estruturação de enunciados em textos por meio de encadeamentos sucessivos; cada um dos enunciados resulta de um ato de fala diferente. O que se afirma não é a relação do tipo lógico existente entre o que é assegurado por duas proposições. Produzem-se, isto sim, dois ou mais enunciados distintos, encadeando-se o segundo sobre o primeiro, considerado tema. Comprova-se 
que são enunciados diferentes resultantes de atos de fala distintos por poderem ser apresentados sob a forma de dois períodos, ou até proferidos por locutores diferentes, recebendo a denominação de encadeadores do discurso. Assim, tanto podem ocorrer entre orações de um mesmo período quanto entre parágrafos de um texto. Esses conectores implicam, então, coordenação semântica e mais de um universo de crenças.

Guimarães (2002) diz que a função da coordenação não é simplesmente adicionar orações, mas sim encadeá-las sucessivamente transformando-as em texto. Por essa razão, diz ele, as conjunções coordenativas, na coordenação semântica, aparecem não só entre orações de um mesmo período, mas também encadeando orações de períodos diferentes, ou até parágrafos entre si. São por isso consideradas encadeadores do discurso. Já as conjunções subordinativas, quando ligam apenas proposições dentro do mesmo enunciado, transformando predicados simples em complexos e dando origem às frases ligadas, constituem simplesmente conectivos ou operadores do tipo lógico.

Operadores argumentativos ou do discurso, termo cunhado por Oswald Ducrot, designam certos elementos da gramática da língua que têm por função indicar a forma argumentativa dos enunciados, a direção para a qual apontam. São elementos de valor essencialmente argumentativo que orientam o texto numa dada direção argumentativa. São importantes marcas linguísticas da enunciação, pois a argumentatividade não é algo apenas acrescentado ao uso linguístico, mas, ao contrário, inscrito na própria língua. Sustenta-se que o uso da linguagem é inerentemente argumentativo. No momento em que se interage através da linguagem, pretende-se orientar os enunciados produzidos no sentido de determinadas conclusões, com exclusão de outras. Se a língua permite falar sobre as coisas, seu objetivo primeiro não é descrevê-las, não é informar sobre o que elas são, mas provocar uma avaliação, orientar para uma conclusão, já que, segundo esses teóricos, a argumentatividade é mais importante que a informatividade.

Assim, a macrossintaxe do discurso (ou a semântica argumentativa) vem recuperar tais elementos porque são justamente eles que determinam o valor argumentativo dos enunciados. Para exame dos operadores argumentativos faz-se necessária uma recapitulação das noções de escala argumentativa ${ }^{4}$ e de classe argumentativa formuladas por Ducrot. A classe argumentativa consiste em dois ou mais argumentos orientados no mesmo sentido, ou seja, para uma mesma conclusão. Diz-se 
que $p$ é um argumento para a conclusão $r$, se $p$ é apresentado como o que leva o interlocutor a concluir $r(\mathrm{KOCH}, 2006)$. Exemplo ${ }^{5}$ :

5. João é o melhor candidato. (conclusão $r$ )

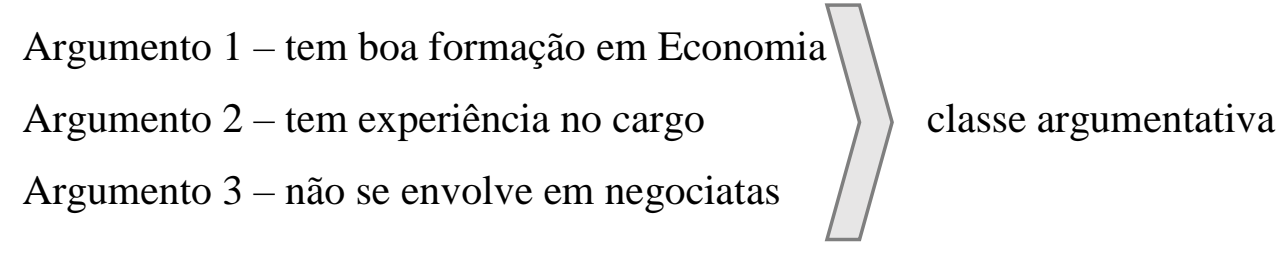

$\left.\begin{array}{l}\text { Argumento } 2 \text { - tem experiência no cargo } \\ \text { Argumento } 3 \text { - não se envolve em negociatas }\end{array} \quad\right\rangle$ classe argumentativa

Etc. (Todos os argumentos têm o mesmo peso para levar o alocutário a concluir $r$ ).

Quando dois ou mais enunciados - p, p', p”... - de uma classe se apresentam em gradação de força (escala graduada) crescente no sentido de uma mesma conclusão $r$, tem-se a escala argumentativa:

6. A apresentação foi coroada de sucesso (conclusão $r$ )

Argumento 1 - estiveram presentes personalidades do mundo artístico

Argumento 2 - estiveram presentes pessoas influentes nos meios políticos

Argumento 3 - esteve presente o Presidente da República (argumento mais forte)

Pode-se representar graficamente a escala argumentativa da seguinte forma, com o topo da pirâmide representando o argumento mais forte:

7. r: A apresentação foi coroada de sucesso: 
Figura 1: Escala argumentativa

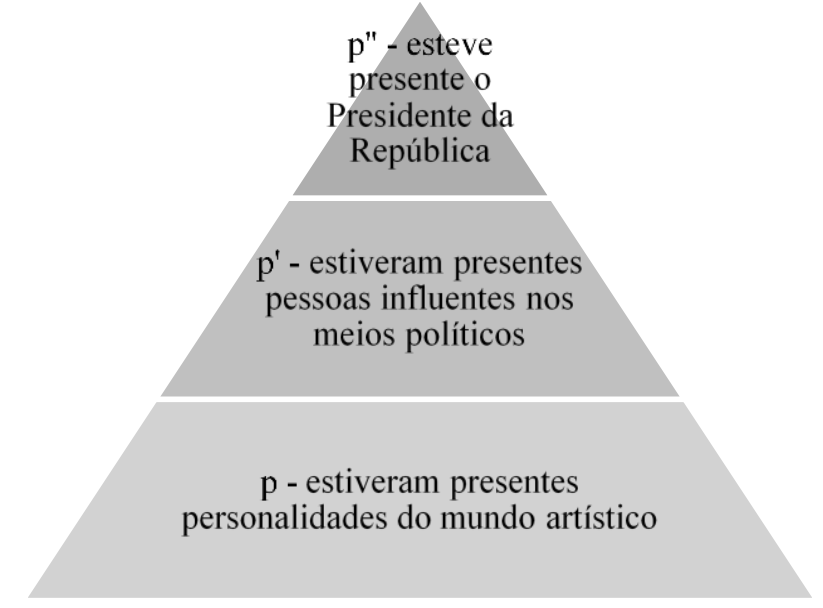

Fonte: MARINS, 2021.

Se, no entanto, a mesma conclusão for negada, invertem-se os elementos da escala, com a base da pirâmide representando o argumento mais forte:

8. r: A apresentação não teve sucesso:

Figura 2: Escala argumentativa

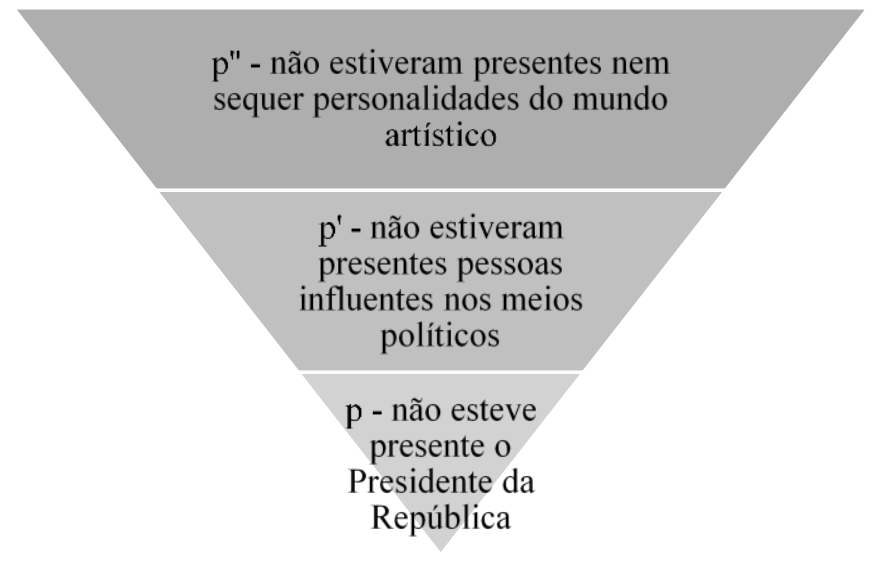

Fonte: MARINS, 2021.

Pode-se tratar a escala argumentativa com certos operadores argumentativos que estabelecem a hierarquia dos elementos na escala:

9. $\mathrm{r}=$ Ânderson é ambicioso 
Figura 3: Escala argumentativa

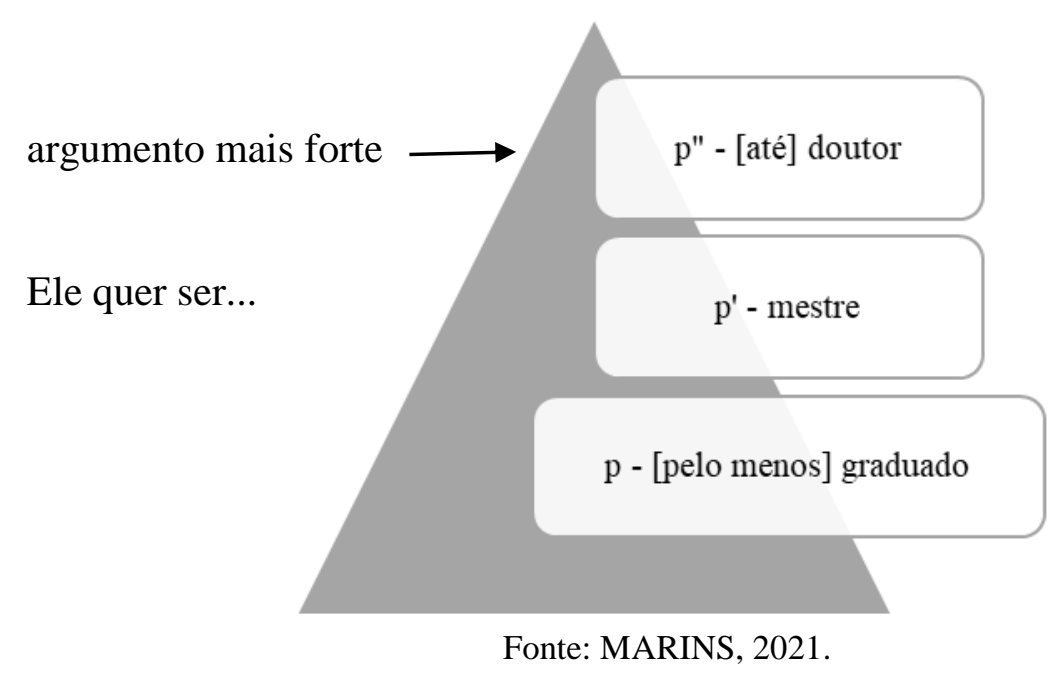

Assim, entre os principais operadores existem os que, de acordo com Koch (2010):

- assinalam o argumento mais forte para uma determinada conclusão $r$, como, por exemplo, os operadores mesmo, até, até mesmo, inclusive ou, então, o argumento mais fraco, como ao menos, pelo menos, no mínimo;

- somam argumentos a favor de uma mesma conclusão, ou seja, argumentos que integram uma mesma classe argumentativa, como, por exemplo, e, também, ainda, em (= e não), não só... mas também, tanto...como, além de..., além disso..., a par de..., etc.

- introduzem uma conclusão relativa a argumentos apresentados em enunciados anteriores, como portanto, logo, por conseguinte, pois, em decorrência, etc.

- introduzem argumentos alternativos que levam a conclusões que diferem ou se opõem, como ou, ou então, quer... quer, seja... seja, etc.

- introduzem uma justificativa ou explicação relativa ao enunciado anterior, como porque, que, já que, pois, etc.

- contrapõem argumentos orientados para conclusões contrárias, como mas, porém, contudo, todavia, no entanto, embora, ainda que, posto que, apesar de, etc.

- têm por função introduzir no enunciado conteúdos pressupostos, como já, ainda, agora, etc. 
Importante observação que Ducrot (1977) nos apresenta a partir do trabalho de Bally (1944) diz respeito aos dois modos de composição entre enunciações, ou seja, a coordenação e a subordinação, dos quais passaremos a tratar a seguir.

Bally destaca a coordenação, que se trata de uma noção de ordem semântica e não morfológica ou sintática. Ducrot acolhe a ideia de Bally em relação ao fato de a coordenação poder realizar-se sem qualquer conjunção aparente ou quando duas enunciações estão ligadas por uma conjunção.

Haverá, portanto, coordenação semântica entre enunciações $A$ e $B$ se:

Figura 4: Coordenação semântica

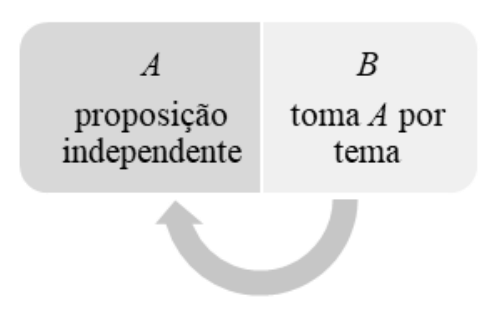

Fonte: MARINS, 2021.

Dessa forma, A é uma proposição autônoma correspondente a um ato de enunciação completo que permanece idêntico a si mesmo quer $A$ seja ou não seguido de $B$, além de comportar um tema e um comentário. Ao passo que $B$ toma $A$ por tema, apresentando-se como um comentário concernente a $A$. Em um período como

10. Cheguei em casa; vou descansar,

a primeira afirmação - Cheguei em casa - realiza um ato de asserção totalmente diferente da segunda - vou descansar -, que se instaura como um comentário referente à afirmação precedente: 
Figura 5: Coordenação semântica

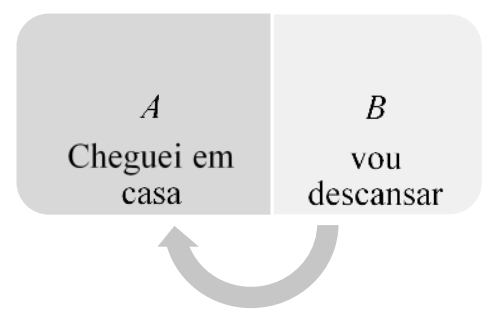

Fonte: MARINS, 2021.

Com efeito, nota-se uma distinção entre coordenação semântica e coordenação sintática, visto que esta relaciona segmentos com a mesma função, ao passo que aquela se fundamenta nos atos de enunciação realizados por ocasião da produção dos enunciados, podendo ocorrer sem qualquer marca gramatical aparente (p. ex. conjunção) ou mesmo quando duas enunciações $(A$ e $B$ ) estão unidas por uma conjunção dita de "subordinação" (DUCROT, 1977). No exemplo, $A$ pode ser analisado como objeto de um ato de linguagem independente e $B$ como consequência de $A$, a comportar, pois, como parte integrante, uma referência a $A$.

Para Ducrot, o terceiro modo de composição entre enunciações consiste no que Bally denomina frase ligada (soldadura). Neste caso, nenhuma das duas orações é objeto de um ato de enunciação compreensível independentemente do outro, ou seja, as duas orações correspondem a um único intento. Em 11, proposto por Ducrot, fica clara a questão:

11. Quem pode mais chora menos.

Assim, não se afirma um poder e, depois, em relação com esse poder, um chorar, mas, em vez disso, se afirma uma relação entre poder e chorar.

A distinção entre frase ligada e coordenação serve para diferenciar conjunções que a gramática classifica indistintamente na chancela da subordinação. Considere-se os quatro enunciados a seguir ${ }^{6}$ :

12. Pedro veio para que Tiago partisse.

13. Pedro veio, de modo que Tiago partiu. 
14. Pedro veio porque Tiago partiu.

15. Pedro veio, pois Tiago partiu.

Para descrever as oposições para quel de modo quel e porquel pois devem-se observar diferenças na natureza das relações expressas (finalidade/consequência, causa/prova), além de diferenças na organização interna dos períodos. Assim, 16, diferentemente de 15, não pode ser objeto de uma interrogação, nem de uma negação, ou seja, não temos

16. Pedro veio, de modo que Tiago partiu?,

nem

17. Pedro não veio, de modo que Tiago partiu em seu encalço.

Caso encontremos tais enunciados, a negação e a interrogação não incidem sobre a própria relação de consequência.

Além disso, de modo que não pode ser modificado por somente:

18. Pedro veio somente de modo que Tiago partiu.

Ou introduzir a oração consecutiva na perífrase $E$... que:

19. É de modo que Tiago partiu que Pedro veio.

Essas transformações não podem se aplicar ao período 15, com pois. Em compensação, podem ser aplicadas com os períodos 12 (Pedro veio para que Tiago partisse) e 14 (Pedro veio porque Tiago partiu), construídos com para que e porque, o que leva a sugerir que se dê a 12 e 14 uma estrutura comum, diferente da de 13 (Pedro veio, de modo que Tiago partiu) e 15 (Pedro veio, pois Tiago partiu).

A diferença entre os dois tipos de períodos reside no fato de 12 e 14 serem frases ligadas, porque o locutor, nesse caso, as emprega com intenção de apontar a relação existente entre as duas orações de que cada uma das frases ligadas é constituída (DUCROT, 1977). Logo, indica-se o objetivo ou a causa da vinda de Pedro, daí ser possível introduzir expressões como somente ou é.. que, que tomam diretamente como alvo essa relação, que, por sua vez, pode também ser negada ou colocada em dúvida por 
meio de uma negação ou interrogação. Diferentemente, em 13 e 15, construídas com de modo que e pois, pode-se falar em coordenação, entendendo por isso que o emprego desses períodos equivale a realizar, de acordo com Ducrot, duas enunciações sucessivas. Anuncia-se que Pedro veio para, em seguida, apresentar, uma vez admitido esse primeiro fato, um outro fato, que é apresentado como consequência ou como prova. Não é, portanto, a relação existente entre os dois fatos que está em jogo, mas a afirmação de dois fatos, introduzindo o segundo por intermédio de sua relação com o primeiro.

Há, também, uma diferença de ordem estrutural entre os dois tipos de períodos, caracterizada pela sua organização interna, no modo como se articulam seus constituintes semânticos. Entrevendo-se uma solução, pode-se acrescentar a Pedro, sujeito da frase 14, um determinante do tipo só, mesmo, também:

20. Pedro só veio porque Tiago partiu.

Ducrot (1977) defende que, nesse caso, teremos duas leituras possíveis:

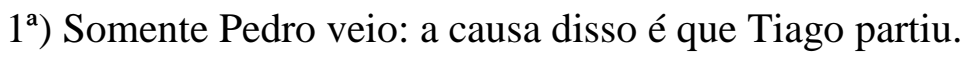

A causa da partida de Tiago é que ninguém mais além de Pedro tenha vindo, coerentemente com a regra de encadeamento

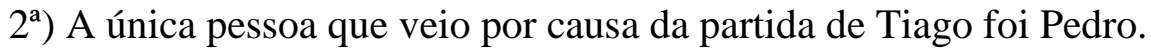

Em contrapartida, só se apresenta uma dessas leituras imagináveis para os enunciados construídos da mesma maneira a partir de 13:

21. Só Pedro veio, de modo que Tiago partiu.

Pode-se descrever 21 como constituído por duas orações Só Pedro veio e Tiago partiu, ligadas pela coordenação de modo que. Faz-se, ainda, necessária uma descrição análoga para 15, que conteria assim as proposições Só Pedro veio e Tiago partiu, ligadas por pois.

Para Ducrot (1977), os períodos em que se constata a coordenação teriam em sua estrutura semântica uma sucessão de duas proposições. Assim, 20, encarado em sua primeira interpretação, é paralela à única leitura possível para 21.

Para explicar as várias transformações (interrogativa e negativa), basta dizer que 12 (Pedro veio para que Tiago partisse) e 14 (Pedro veio porque Tiago partiu) podem 
sofrer, e que 13 (Pedro veio, de modo que Tiago partiu) e 15 (Pedro veio, pois Tiago partiu) não podem.

Ducrot dá à noção de frase ligada uma definição de tipo estrutural, ou seja, uma frase ligada é a que admite um só predicado, constituído pela fusão de predicados elementares, ou, como é o caso quando 20 é lido de acordo com sua segunda interpretação, pela fusão de um predicado "vir" e uma oração "Tiago partiu".

Certos enunciados, como 12, 14 e 20, podem ser vistos ora como períodos ligados, ora como produtos de uma coordenação. Outros, no entanto, só se podem compreender como coordenações, como aqueles construídos com pois ou de modo que.

Há enunciados que devem ser compreendidos como frases ligadas, que atribuem um predicado complexo único a um sujeito único, como é o caso dos enunciados negativos ou interrogativos nos quais figuram porque ou para que:

\section{Pedro virá para que Tiago parta?}

A rigor, quando duas estruturas forem possíveis haverá ambiguidade, isto é, estaremos diante de dois enunciados homônimos.

A noção-chave, segundo Ducrot (1977), para determinar a diferença estrutural entre coordenação e frase ligada é a de "predicado complexo". Para introduzir essa noção, Ducrot opõe-se à tese atribuída a Chomsky de que toda complexidade, num enunciado, deriva do fato de ele comportar, em sua estrutura profunda, uma multidão de enunciados imbricados uns aos outros. Na verdade, Ducrot sustenta a existência de outra fonte de complexidade, manifestada sobretudo nas frases ligadas, que resulta da estrutura interna do predicado. O predicado, chamado por ele de "complexo", é nesses casos composto, quer por um predicado elementar sobre o qual operaram diferentes operadores, quer pelo amálgama de predicados elementares, ou de predicados elementares e de orações. Tais possibilidades se combinam mutuamente.

Os períodos contendo porque, como vimos, podem ser considerados estruturalmente ambíguos, ora interpretados como coordenações de orações, ora como frases ligadas comportando um único predicado complexo. Coordenação e frase ligada, e a introdução correlativa da noção de predicado complexo são de grande relevância ao se tratar do componente linguístico e de calcular a significação dos enunciados.

Vejamos este outro caso trazido por Ducrot (1977): 


\section{João veio porque se aborrecia.}

O enunciado é constituído pelo sujeito "João" e pelo predicado complexo "vir por aborrecer-se". Introduz-se no componente linguístico um operador porque, que transforma dois predicados "Pr1" e "Pr2" num predicado complexo "Pr1 porque Pr2. As noções de predicado complexo e de coordenação não repousam tão-somente numa espécie de "intuição semântica", que faz "sentir" a existência de tipos de organização diferentes. Elas têm a função de agir no funcionamento do componente linguístico, componente este que toma como ponto de partida os enunciados considerados fora de qualquer contexto e atribui-lhes significações (DUCROT, 1977, p. 124).

A noção de predicado complexo, introduzida por Ducrot (1977) a partir da formulação de Bally, que ocorre quando temos frases ligadas busca deixar clara a diferença estrutural entre os períodos assim organizados e os organizados por coordenação semântica. Nos períodos de frases ligadas, as palavras utilizadas para ligar as orações cumprem o papel de conectivos ou operadores lógicos que encaixam uma oração em outra. Assim, fazem da primeira um termo da segunda, na medida em que as duas passam a constituir uma única oração com predicado complexo: um enunciado único que resulta de um só ato de enunciação. Tais operadores concebem relações predominantemente lógicas entre as orações que ligam. A intenção do locutor, neste caso, consiste em deixar clara a relação lógica entre as orações. Já nos períodos de coordenação semântica, são utilizados os operadores argumentativos ou discursivos para ligar as orações. Tais operadores encadeiam orações (enunciados) a fim de estruturá-las em texto, isto é, constituindo um discurso. Neste caso, temos dois enunciados que resultam de dois atos de enunciação diferentes e sucessivos. Portanto, podem aparecer encadeando tanto orações de um mesmo período quanto orações de períodos diferentes ou períodos e parágrafos entre si e também um enunciado com o modo de enunciação do outro (TRAVAGLIA, 1986). Ducrot (1977), então, propõe critérios para verificar se se trata ou não de duas proposições, se temos coordenação semântica ou frases ligadas. Esses critérios dizem respeito ao alcance da interrogação e da negação, ao encadeamento, à extraposição e ao escopo da quantificação:

a) Alcance da interrogação e negação: nas frases ligadas, a interrogação e a negação incidem sobre todo o enunciado; na coordenação semântica, a oração 
introduzida pelo operador argumentativo não pode ser objeto de interrogação ou ser negada, neste caso a interrogação ou negação incide só sobre a outra oração:

24. A menina se cortou porque brincava com a faca. - FRASE LIGADA ${ }^{\text {ii }}$

25. O candidato estudou, pois tinha ciência de que a prova não seria fácil. COORDENAÇÃO SEMÂNTICA ${ }^{\mathrm{iii}}$

- Interrogação

26. A menina se cortou porque brincava com a faca?

27. O candidato estudou, pois tinha ciência de que a prova não seria fácil?

- Negação

28. [A menina não se cortou porque brincava com a faca].

29. [O candidato estudou], pois tinha ciência de que a prova não seria fácil. ${ }^{\text {iv }}$

b) Encadeamento: consiste em transformar as orações em subordinadas de uma outra. As frases ligadas encadeiam-se como um todo a orações do tipo "Creio que", "Parece que", "Afirmo que", "Pergunto se", etc, ao passo que nas coordenadas semânticas só a primeira se encadeia com tais orações:

30. Parece que [a menina se cortou porque brincava com a faca].

31. Parece que [o candidato estudou], pois tinha ciência de que a prova não seria fácil.

c) Extraposição: consiste em tematizar um elemento do enunciado por meio de um procedimento linguístico do tipo é... que, somente, isto é, extrapor consiste em um processo de eleger no interior do conteúdo de um enunciado um elemento que centralizará o foco informacional deste conteúdo, com auxílio de recursos linguísticos

\footnotetext{
ii Neste caso, nenhuma das duas orações é objeto de um ato de enunciação compreensível independentemente do outro, ou seja, as duas orações correspondem a um único intento.

iii Neste caso, temos dois enunciados que resultam de dois atos de enunciação diferentes e sucessivos.

${ }^{i v}$ Em (26) e (28), nota-se uma maior integração ([+interdependência]) entre os segmentos que compõem a relação causal, enquanto que em (27) e (29), nota-se uma relação mais frouxa.
} 
(VOGT, 1989). Nas frases ligadas, a oração, ligada por um operador lógico, pode ser extraposta; na coordenação, a oração, que é iniciada por um operador argumentativo, não pode se extraposta. Exemplos:

32. É porque brincava com a faca que a menina se cortou.

33. Somente porque brincava com a faca, a menina se cortou.

34. A menina se cortou somente porque brincava com a faca.

35. *É pois tinha ciência de que a prova não seria fácil que o candidato estudou.

36. *Somente pois tinha ciência de que a prova não seria fácil, o candidato estudou.

37. *O candidato estudou somente pois tinha ciência de que a prova não seria fácil.

d) Escopo da quantificação: nas frases ligadas, a quantificação incide sobre todo o enunciado e na coordenação somente sobre a primeira oração.

38. As maravilhas de Iavé não se resumem a atos de libertação, pois a disciplina que Ele realiza também é seu amor em ação.

39. Os peões da empreiteira da obra do palácio quebraram barracões do acampamento onde viviam porque encontraram vermes na carne que lhes era servida.

\section{- Quantificação}

40. [Muitas maravilhas de Iavé não se resumem a atos de libertação], pois a disciplina que Ele realiza também é seu amor em ação.

41. [Muitos peões da empreiteira da obra do palácio quebraram barracões do acampamento onde viviam porque encontraram vermes na carne que lhes era servida].

\section{CONSIDERAÇÕES FINAIS}


Neste estudo, mostrou-se que as conjunções causais e explicativas agasalham características peculiares, buscando-se enfatizar essa questão sobretudo pelo viés semântico. O efeito de sentido de uma conjunção não é o sentido que ela toma num contexto, ou as modificações que lhe traz o contexto, mas ao contrário, o que está em jogo é a mudança produzida nesse contexto pela introdução de determinada conjunção. $\mathrm{Ou}$ seja, as nuanças de significados entre essas conjunções baseiam-se no comportamento diferenciado de certas orações introduzidas por esses conectores. A especificação quanto ao emprego das conjunções que as introduzem pode ser atribuída a fatores de ordem semântica, discursiva e, por que não, pragmáticas.

Com efeito, rever as classificações propostas pelas gramáticas tradicionais quanto às orações causais e explicativas possibilitou dois procedimentos: discutir aspectos semânticos da argumentatividade no uso de conectivos que introduzem a explicação e a causa e apresentar nuanças semânticas que distinguem as conjunções pois e porque. Assim, pois e porque (no seu uso em que permite a ruptura do bloco) têm valor explicativo, pois introduzem um ato de fala que explica o ato de fala de outra oração. Por outro lado, a conjunção porque, ao formar um único bloco com a outra oração, tem valor causal. Ela é a causa para o fato enunciado pelo verbo da outra oração.

\section{Referências}

BALLY, Charles. Linguistique Génerale et linguistique française. 2. ed. A. Francke S.A. Berne, 1944.

DUCROT, Oswald. Dizer e não dizer. Princípios de semântica linguística. São Paulo: Cultrix, 1977.

GONÇALVES, Miguel. O conceito de conector nos diversos estádios do sistema teórico de Ducrot e da sua equipa. In: DUARTE, Isabel Margarida; BARBOSA, Joaquim; MATOS, Sérgio; HÜGGEN, Thomas. (Org.). Actas do Encontro Comemorativo dos 25 anos do Centro de Linguística da Universidade do Porto (CLUP), Porto, v. 2, p. 203216, 2002.

GUIMARÃES, Eduardo. Texto e argumentação: um estudo das conjunções do português. Campinas: Pontes, 2002. 
KOCH, Ingedore Grunfeld Villaça. A inter-ação pela linguagem. São Paulo: Contexto, 2010 .

KOCH, Ingedore Grunfeld Villaça. Argumentação e linguagem. São Paulo: Cortez, 2006.

MARINS, Ânderson Rodrigues. Conjunções causais e explicativas do português em perspectiva semântico-argumentativa. Campinas - SP: Pontes editores, 2021.

MARINS, Ânderson Rodrigues. Linguística e gramática: fatos do sistema. Rio de Janeiro: Autografia, 2017.

TRAVAGLIA, Luiz Carlos. Da distinção entre orações coordenadas explicativas e orações subordinadas adverbiais causais: uma questão sintática, semântica ou pragmática? Letras \& Letras, Uberlândia, v. 2, n. 2, p. 241-286, jul. /dez. 1986.

VOGT, Carlos. Linguagem, pragmática e ideologia. São Paulo: Hucitec, 1989.

Recebido em: 27/01/2021

Aceito em: 31/03/2021

\footnotetext{
${ }^{1}$ Frase ligada trata-se, segundo Koch (2006, p. 129), de "um único enunciado, resultante de um só ato de linguagem, visto que nenhuma das proposições é objeto de um ato de enunciação compreensível independentemente do outro. Exemplo: Jorge não compareceu à homenagem porque estava enfermo".

2 A introdução correlativa da noção de predicado complexo é de grande relevância ao se tratar do componente linguístico e de calcular a significação dos enunciados. Vejamos este caso trazido por Ducrot (1977): João veio porque se aborrecia. O enunciado é constituído pelo sujeito "João" e pelo predicado complexo "vir por aborrecer-se". Introduz-se no componente linguístico um operador porque, que transforma dois predicados "Pr1" e "Pr2" num predicado complexo "Pr1 porque Pr2.

${ }^{3}$ Como em: "Conte histórias para seu filho. Porque ele dará asas à imaginação".

${ }^{4}$ A rigor, é através das escalas argumentativas que Ducrot inaugura a análise dos fenômenos ligados à argumentação. Do aparelho conceptual aí apresentado - classe argumentativa, valor argumentativo, orientação argumentativa - e não obstante a importância que tais noções assumirão no seio da própria teoria, a que mais sobressai, pelo seu carácter fundador, é, sem dúvida, a de classe argumentativa (GONÇALVES, 2002, p. 207).

${ }^{5}$ Os exemplos a seguir estão em Koch (2010).

${ }^{6}$ Os exemplos a seguir são de Ducrot (1977).
} 